\title{
EVALUATION OF MASS DRUG ADMINISTRATION CAMPAIGN AGAINST LYMPHATIC FILARIASIS AT BIDAR DISTRICT
}

Mubeen Hussain, Sunil Kumar D, S.R.Nigudgi, Shrinivas Reddy.

\author{
1. Assistant Professor Department of Community Medicine, M.R. Medical College, Gulbarga. \\ 2. Assistant Professor Department of Community Medicine, JSS Medical College, Mysore. \\ 3. Professor Department of Community Medicine, M.R.Medical College, Gulbarga. \\ 4. Statistician, Department of Community Medicine, M.R.Medical College, Gulbarga
}

\section{CORRESPONDING AUTHOR:}

Dr Mubeen Hussain,

H.No 1-940/A/1,

Opp Raju kirana shop,

Housing board colony Road,

Rahmatnagar , Gulbarga, Karnataka. 585102.

E-mail: mubeenhussain53@gmail.com

\begin{abstract}
INTRODUCTION: - Lymphatic Filariasis is one of the important public health and socioeconomic problem faced by many developing countries in the world It is endemic in 83 countries and nearly 120 million people are affected worldwide of whom about 40 million are incapacitated and disfigured by the disease. It is one of the world's leading causes of permanent and long-term disability. The National Health Policy 2002 aims at Elimination of Lymphatic Filariasis by 2015. The strategy for achieving the goal of elimination is by Annual Mass Drug Administration of DEC for 5 years or more to the population. AIMS AND OBJECTIVES: To find out the coverage and compliance of MDA programme MATERIALS AND METHODS: One cluster (ward) from urban area and three clusters (three primary health centre's (PHC)) from rural areas were selected randomly from the list of urban wards and PHC's where the MDA was carried out. From the PHC's, one sub center was selected and then one village from that sub center was selected randomly from the list of sub centers and villages in the PHC's. In those selected villages, 50 randomly selected households were covered. All the available individuals at the time of interview in the household were taken. RESULTS: Majority of the studied population were in the age group of 15-60(56.54\%) years and Majority of them were males $480(51.90 \%)$. Compliance rate was $77.3 \%$.The most common reason for not consuming the tablets were 54(25.72\%) not present at home when the tablets were distributed followed by $48(22.86 \%)$ where drug given but had no information about the dose and reason and $42(20 \%)$ due to the fear of side effects. Only $8(1.12 \%)$ developed minor adverse reactions. About 592(64\%) of the studied population were aware about the MDA programme and $368(62.16 \%)$ got aware from media and posters and 224(37.84\%) from Anganwadi, ASHA and other health workers. CONCLUSION: There is a need to strengthen the MDA programme planning and implementation in terms of creating awareness through appropriate media in the community
\end{abstract} KEYWORDS: Lymphatic Filariasis, DEC, MDA

INTRODUCTION: Lymphatic Filariasis, commonly known as elephantiasis, is a neglected tropical disease. The disease was recorded in India as early as 6th century BC by the famous Indian physician, Susruta in his book 'SusrutaSamhita'. Lymphatic filariasis (LF) is one of the important 
public health and socioeconomic problem faced by many developing countries in the world.2 ${ }^{2}$ It is endemic in 83 countries and territories, with more than a billion people at risk of infection. Nearly 120 million people are affected worldwide of whom about 40 million are incapacitated and disfigured by the disease. It is one of the world's leading causes of permanent and long-term disability with an estimated 5.1 million disability adjusted life years (DALYs) are lost due to this disease. 3,4

The National Health Policy 2002 aims at Elimination of Lymphatic Filariasis by 2015. The strategy for achieving the goal of elimination is by Annual Mass Drug Administration of DEC for 5 years or more to the population excluding children below two years, pregnant women and seriously ill persons in affected areas to interrupt transmission of disease ${ }^{5}$. The National Filarial Control Programme (NFCP) was launched in1955 for the control of Bancroftian filarial and now National Health Policy Goal is to eliminate lymphatic Filariasis from India by the year 2015 6, 7 .

In India, 243 districts are identified as endemic districts with 29 million people being parasite carriers and 22 million with chronic disease. Eight districts are identified as endemic in Karnataka and Bidar district is one of them. MDA of single dose DEC once in a year was started in 2004.Programme was based on a house-to-house approach involving health department staff, anganwadi workers, self-help groups, youth clubs, medical college staff and students, etc. Prior to each round of drug distribution, orientation and training sessions were conducted in each PHC level for all the participants. Campaigns through mass media (Television, Radio and Newspapers) and banners, pamphlets, posters, were also conducted in most of the areas. Predictions indicate that at least $90 \%$ consumption is required to achieve the goal of elimination with five rounds of annual DEC based MDA and 11 rounds are required if the coverage is $60 \%{ }^{8}$.Current approaches to drug delivery are able to achieve only $40-60 \%$ of coverage if MDA executed by regular health services ${ }^{9}$. Therefore, the principal challenge before the planners, programme managers and researchers is to develop effective and sustainable drug delivery strategies and also to find out the short comings of recently conducted programme with reference to coverage and compliance and to further improve strategies for future rounds.

\section{AIMS AND OBJECTIVES:}

1. To find out the coverage of MDA.

2. To find out the side effects of DEC.

3. To find out the compliance of MDA by the people.

4. To find out the reasons for non compliance.

\section{MATERIAL AND METHOD:}

\section{$>$ Study area}

The study areas were one of the filarial endemic districts (Bidar) in Karnataka state.

Study design This was a cross-sectional survey.

$>$ Study period

The field part of the study was conducted during February 2010. 


\section{ORIGINAL ARTICLE}

\section{$>$ Study population}

All the sampled eligible population who belong to the MDA campaign area.925 study subjects were interviewed.

$>$ Exclusion criteria

The eligible population did not include pregnant and lactating women, children below two years of age and seriously ill persons

$>$ Methodology

One cluster (ward) from urban area and three clusters (three primary health centre's (PHC)) from rural areas were selected randomly from the list of urban wards and PHC's where the MDA was carried out. From the PHC's, one sub center was selected and then one village from that sub center was selected randomly from the list of sub centers and villages in the PHC's. In those selected villages, 50 randomly selected households were covered. All the available individuals at the time of interview in the household were taken.

$>$ Survey

House to house field survey was conducted and filled the proforma using personal interview method. Informal consent was obtained from the participants.

$>$ Ethics

The study was cross sectional and does not involve patient intervention methods; hence, ethical issue does not arise.

\section{$>$ Limitation}

This study was conducted after 3 months of MDA campaign which is a limitation (recall bias). This survey assessed only the coverage aspect and not the entire MDA implementation programme.

\section{$>$ Analysis and statistical methods}

The data were collected in a pretested Performa, computed in Microsoft Excel and analyzed using the statistical program SPSS. The data were used to calculate frequencies and proportions.

RESULTS: Table no 1 shows Age and sex wise distribution of the study population where majority of them were in the age group of 15-60(56.54\%) years followed by 6-14(24.32\%) years and least in the age group 2-4(9.41\%) years respectively. Majority of them $480(51.90 \%)$ were males and $445(8.10 \%)$ were females. Table no 2 shows the distribution of the study population based on the consumption of DEC Tablets. Among those who received tablets, it was observed that only 925 of the individuals received the adequate dose and only $715(77.3 \%)$ consumed the tablets and about $210(22.7 \%)$ did not consumed the DEC tablets. Hence, compliance rate was only $77.3 \%$.

Table no 3 shows the reasons for non compliance to DEC Tablet among the eligible population. Out of the 210 studied population who did not consumed the tablet, the most common reason $54(25.72 \%)$ were not present at home when the tablets were distributed followed by $48(22.86 \%)$ where drug given but had no information about the dose and reason. $42(20 \%)$ of the studied population did not consume the tablet due to the fear of side effects followed by $37(17.61 \%)$ who were not feeling well. Other reasons $29(13.81 \%)$ include, on some other medication, some families expressed their difficulty in giving tablet to children in 2-5 year, old age, previous surgery and not at risk. 
Table no 4 shows the distribution of the study population who developed adverse reaction to DEC Tablet. Out of the 715 study population who consumed the tablets, only $8(1.12 \%)$ developed minor adverse reactions like nausea, vomiting, Headache, giddiness, gastric acidity etc. Table no 5 shows the distribution of the study population regarding their knowledge about MDA Programme about 592(64\%) of the studied population were aware about the MDA programme and 333(36\%) were not aware about the MDA programme. Table no 6 shows the distribution of the study population regarding their source of knowledge about MDA Programme about 368(62.16\%) got aware from media and posters and 224(37.84\%) from Anganwadi, ASHA and other health workers

DISCUSSION: The present study is a qualitative cross sectional, covering a target population of 925 from four clusters. According to our survey among those who received DEC tablets, it was observed that among 925 studied population only 715 (77.3\%) consumed the tablets and about $210(22.7 \%)$ did not consumed the DEC tablets. Hence, compliance rate was only $77.3 \%$.Though the non compliance percentage is less, it can be made lesser by reorienting the drug distributors and proper supervision. In a study done by B V Babu ${ }^{10}$ in Orissa compliance rate was $42 \%$. Similarly a study done by Abhay et al ${ }^{11}$ found that the overall coverage was $79.7 \%$ but the compliance was only $43.04 \%$.It was found that majority of population swallows one DEC tablet in morning \& two in night mainly because the drug distributor did not specify them properly. Hence In countries like India, where annual MDA is an economic option, and the existing government health care system is capable of conducting the programme, although more inputs are required to achieve desired levels of compliance.

Out of the 210 studied population who did not consumed the tablet, the most common reason $25.72 \%$ were not present at home when the tablets were distributed followed by $22.86 \%$ where drug given but had no information about the dose and reason.20\% of the studied population did not consume the tablet due to the fear of side effects followed by $17.61 \%$ who were not feeling well at the time of distribution. Other reasons $13.81 \%$ include, on some other medication, some families expressed their difficulty in giving tablet to children in 2-5 year, old age, previous surgery and not at risk. Similarly a study done by Abhay et al ${ }^{11}$ found the most common cause of non compliance to DEC in present study was fear of side effects among the beneficiaries (47.51\%).Similar observations were noted by Karmakar P Roy et al ${ }^{12}$ found that the most frequent cause was fear of side effects (36.84\%). KS Ravish et al ${ }^{13}$ reported lack of adequate information as main reason for non-compliance. S. Sabesan et al ${ }^{14}$ after review of the lymphatic Filariasis in India suggested that the programme managers should be encouraged to adopt the principals of 'Directly observed Treatment criteria. Compliance to MDA largely depends on the approach of the drug distributor in implementation of MDA as per guidelines helps to bridge the knowledge gap and it is an important and very cost-effective tool to improve both coverage and compliance of MDA 15 .

In our study out of the 715 study population who consumed the tablets, only $8(1.12 \%)$ developed minor adverse reactions like nausea, vomiting, Headache, giddiness, gastric acidity etc. where majority of them had consumed the tablet before food and in the wrong dosage. Similar observations were noted by Abhay et al ${ }^{11}$ for non compliance to DEC was mainly fear of side effects among beneficiaries (47.51\%) and as such the side effects were very few and minor. Hence this information of the report must be widely publicized in local news papers and cable TV channels in order to alleviate fear of side effects among beneficiaries. Information about the Rapid Response 
Team (RRT) must be widely publicized in order to increase the faith of people which will indirectly result in better compliance ${ }^{16}$.

Regarding the knowledge of the studied population about MDA Programme about $592(64 \%)$ of the studied population were aware about the MDA programme and 333(36\%) were not aware about the MDA programme and regarding their source of knowledge about MDA Programme about 368(62.16\%) got aware from media and posters and 224(37.84\%) from Anganwadi, ASHA and other health workers. The main concept of MDA is to approach every eligible individual in the target community and administer annual single dose of anti-filarial drugs (DEC + Albendazole) ${ }^{15}$. In the study done by KS Ravish et al ${ }^{13}$ it was observed that $41.4 \%$ populations were aware \& 58.6\% were unaware of MDA activity. Similarly a study done by Ashwini Kumar et al ${ }^{16}$ found that $73(31.7 \%)$ respondents came to know about MDA from health personnel, 128(55.6\%) through media (TV, radio and mikes) and 42 (18.2\%) from NGOs. Similarly Mukhopadhyay et al ${ }^{17}$ in their study found that $77.8 \%$ respondents came to know about MDA from health personnel and $20.8 \%$ through media whereas NGO's had very little involvement $(1.2 \%)$. IEC from all possible channels such as involvement of community leaders, school teacher and students, electronic and print media preferably in local languages, appeal from religious leaders should be undertaken to motivate people to participate in the programme and consume DEC tablets.

CONCLUSION: The present study reveals that the consumption of DEC tablets in Bidar district as $77.3 \%$, which is above the minimum target level and better in rural areas. There was hardly any resistance in the community for the program. Efforts are needed to increase the coverage by motivating and sensitizing the community through IEC. There is a need to strengthen the MDA programme planning and implementation in terms of creating awareness through appropriate media in the community. This can be achieved by efficient microplans, improved supervision emphasizing more strongly health work force training thereby to improve the coverage and compliance through community participation. As such, side-effects were very few and minor in our study which also need to be addressed as they may constitute cause of future non-compliance. Information about the Rapid Response Team (RRT) must be widely publicized in order to increase the faith of people which will indirectly result in better compliance.

\section{REFERENCES:}

1. National Vector Borne Disease Control Programme, Directorate General of Health Services, Ministry of Health and Family Welfare, Government of India. Lymphatic Filariasis. Magnitude of disease. Website: Available from:http://nvbdcp.gov.in/fil10.html. [Cited on 2012 Mar 25].

2. Krentel A, Fischer P, Manoempil P, Supali T, Servais G, Rückert P. Using knowledge, attitudes and practice (KAP) surveys on lymphatic filariasis to prepare a health promotion campaign for mass drug administration in Alor District, Indonesia. Trop Med Int Health 2006;11:1731-40

3. World Health Organization. Life in the $21^{\text {st }}$ century: A vision for all. The World Health Report 1998. Available from: http://www.who.int/whr/1998/en/whr98 en.pdf. [Last accessed on 2010 Apr 15]. 
4. World Health Organization. Regional Strategic Plan for Elimination of Lymphatic Filariasis (2004-2007) 2004; 1-2. Available from:

Http://www.searo.who.int/LinkFiles/Newlymphaticfilariasis_Regional_Strategic_Plan_LF 2004-2007.pdf. [Last accessed on 2010 Apr 20]

5. National Vector Borne Disease Control Programme, Directorate General of Health Services, Ministry of Health and Family Welfare, Government of India. Lymphatic Filariasis. Upscaling of mass drug administration. Website: Available from:http://nvbdcp.gov.in/filariasis-new. [Cited on 2012 Mar 26].

6. Kumar P et.al; Evaluation of MDA 2006 in Gujarat.I J.C.M Vol.33 No 1, January 2008: 38-42.

7. B V Babu \& S K Kar. MDA against filariasis in Orissa. Tropical Medicine \& international Health. June 2004; 9(6): 702-709.

8. Global program to eliminate lymphatic filariasis. WHO Wkly Epidemiology Rec 2006; 81: 221-32.

9. Ramaiah KD, Vijay Kumar KN, Ravi R, Das PK. Situation analysis in large urban area of India, prior to launching programme of mass drug distribution to eliminate lymphatic filariasis. Ann J Trop Med Parasitol 2005; 99: 243-5.

10. Babu BV, Kar SK. Coverage, compliance and some operational issues of mass drug administration during the program to eliminate lymphatic filariasis in Orissa, India. Trop Med Internatl Health 2004; 9: 702-9.

11. Nirgude Abhay S, Naik Poonam R, Kondagunta Nagaraj, Reshmi Sidramappa S,Takalkar Anant A, Prasad VG.A study on evaluation of coverage and compliance of Mass drug administration programme 2011 for elimination of lymphatic filariasis in nalgonda district of Andhra Pradesh, India. National Journal of Community Medicine April 2012; 3(2): 288293.

12. Karamkar P Ray, K Mitra, Chatterjee Anirban, PK Jana Bhattacharya S, Lahiri SK. A study on coverage, compliance and awareness about Mass Drug Administration for elimination of lymphatic filariasis in a district of West Bengal, India. J Vector Borne Dis 2011; 48:101-4.

13. KS Ravish, TS Ranganath, Basha S Riyaz. Coverage and compliance of Mass Drug Administration for elimination of lymphatic filariasis in endemic areas of Bijapur district, Karnataka. International Journal of Basic Medical Sciences 2011; 2:86-9.

14.S Sabesan, P Vanamail, KHK Raju, P Jambulingam. Lymphatic Filariasis in India: Epidemiology and control measures. Journal of Postgraduate Medicine 2010;56:232-8.

15. Guidelines on filariasis control in India and its elimination (2009). Available at http://nvbdcp.gov.in/Doc/Guidelines-Filariasis-Elimination-India.pdf. [cited on 2012 Mar 25].

16. Ashwini Kumar, Pawan Kumar, Kondagunta Nagaraj, Divakar Nayak, Lena Ashok \& K. Ashok. A study on coverage and compliance of mass drug administration programme for elimination of filariasis in Udupi district, Karnataka, India. J Vector Borne Dis September 2009; 46: 237-240.

17. Mukhopadhyay AK, Patnaik SK, Sathya Babu P, Rao KNMB. Knowledge on lymphatic filariasis and mass drug administration programme (MDA) in filaria endemic districts of Andhra Pradesh, India. J Vector Borne Dis 2008; 45: 73-5. 


\section{ORIGINAL ARTICLE}

Table no 1:-Age and sex wise distribution of the study population.

\begin{tabular}{|c|c|c|c|c|c|c|}
\hline Age & Male & $\mathbf{\%}$ & Female & $\mathbf{\%}$ & Total & $\mathbf{\%}$ \\
\hline 2-5 years & 43 & $8.96 \%$ & 44 & $9.89 \%$ & 87 & $9.41 \%$ \\
\hline 6-14 years & 118 & $24.58 \%$ & 107 & $24.04 \%$ & 225 & $24.32 \%$ \\
\hline 15-60 years & 277 & $57.71 \%$ & 246 & $55.28 \%$ & 523 & $56.54 \%$ \\
\hline >60 years & 42 & $8.75 \%$ & 48 & $10.79 \%$ & 90 & $9.73 \%$ \\
\hline Total & 480 & $51.90 \%$ & 445 & $48.10 \%$ & 925 & $100 \%$ \\
\hline
\end{tabular}

Table no 2:-Distribution of the population based on the consumption of DEC Tablets

\begin{tabular}{|c|c|c|}
\hline DEC tablet consumed & Frequency & Percentage \\
\hline Yes & 715 & $77.3 \%$ \\
\hline No & 210 & $22.7 \%$ \\
\hline Total & 925 & $100 \%$ \\
\hline
\end{tabular}

Table no 3:-Reasons for non compliance to DEC Tablet among the eligible population

\begin{tabular}{|c|c|c|}
\hline Reasons for non compliance & Frequency & Percentage \\
\hline Not present at home & 54 & $25.72 \%$ \\
\hline Fear of side effects & 42 & $20.00 \%$ \\
\hline Not feeling well & 37 & $17.61 \%$ \\
\hline Drug given at home but no information & 48 & $22.86 \%$ \\
\hline Others & 29 & $13.81 \%$ \\
\hline Total & 210 & $100 \%$ \\
\hline
\end{tabular}

Table no 4:-Distribution of the study population who developed adverse reaction to DEC

\begin{tabular}{|c|c|c|}
\hline Adverse reactions & Frequency & Percentage \\
\hline No & 707 & $98.88 \%$ \\
\hline Yes & 8 & $1.12 \%$ \\
\hline Total & 715 & $100 \%$ \\
\hline
\end{tabular}

Table no 5:-Distribution of the study population regarding their knowledge about MDA Programme

\begin{tabular}{|c|c|c|}
\hline Aware about MDA programme & Frequency & Percentage \\
\hline No & 333 & $36 \%$ \\
\hline Yes & 592 & $64 \%$ \\
\hline Total & 925 & $100 \%$ \\
\hline
\end{tabular}

Table no 6:-Distribution of the study population regarding their source of knowledge about MDA Programme.

\begin{tabular}{|c|c|c|}
\hline Source of knowledge about MDA & Frequency & Percentage \\
\hline Media and posters & 224 & $37.84 \%$ \\
\hline Anganwadi and health workers & 368 & $62.16 \%$ \\
\hline Total & 592 & $100 \%$ \\
\hline
\end{tabular}

